P. O'SHEA ${ }^{*, \mathbb{}}$

S. AKTURK

M. KIMMEL

R. TREBINO

\section{Practical issues in ultra-short-pulse measurements with 'GRENOUILLE'}

School of Physics, Georgia Institute of Technology, Atlanta, GA 30332-0430, USA
Published online: 25 January 2005 • (c) Springer-Verlag 2005

Unfortunately, the publisher printed Figures 7 and 12 incorrectly. The correct figures are given below.
Appl. Phys. B 79, 683-691 (2004)

DOI 10.1007/s00340-004-1644-x

Published online: 29 September 2004
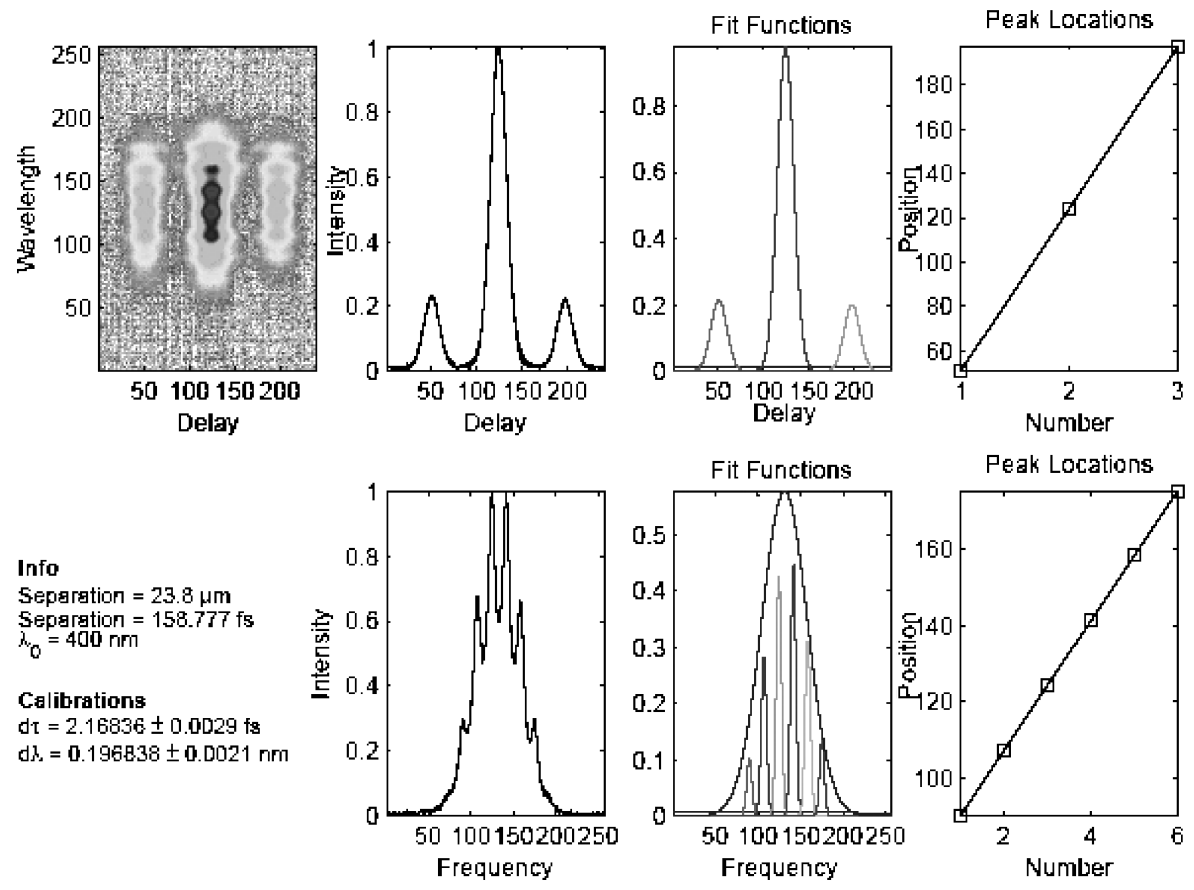

FIGURE 7 Etalon trace and a linear fit to peak locations extracts the calibration knowing only the etalon spacing and center wavelength

Fax: +1-703-704-1753, E-mail: poshea@nvl.army.mil 

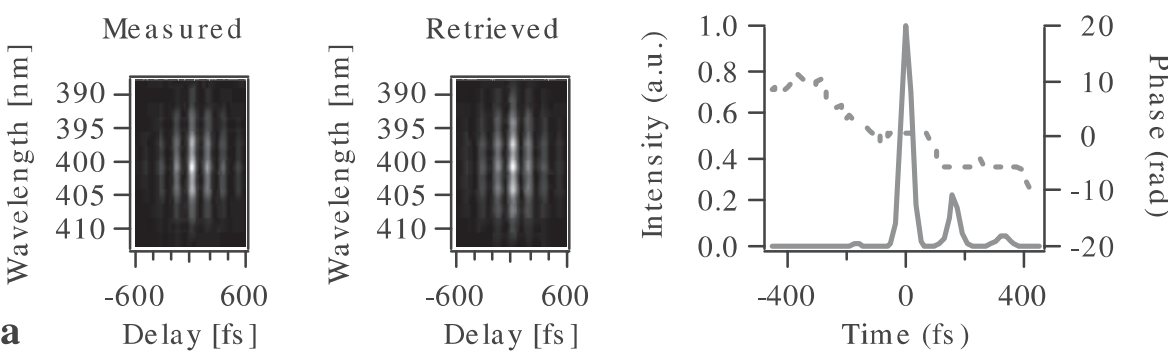

FIGURE 12 Effect of angular misalignment in the delay dimension. (a) Measured and retrieved GRENOUILLE traces of a wellaligned etalon pulse (square root taken for visibility). (b)-(d) As the slit begins to clip the signal beam, the trace distorts, and the algorithm eventually converges incorrectly
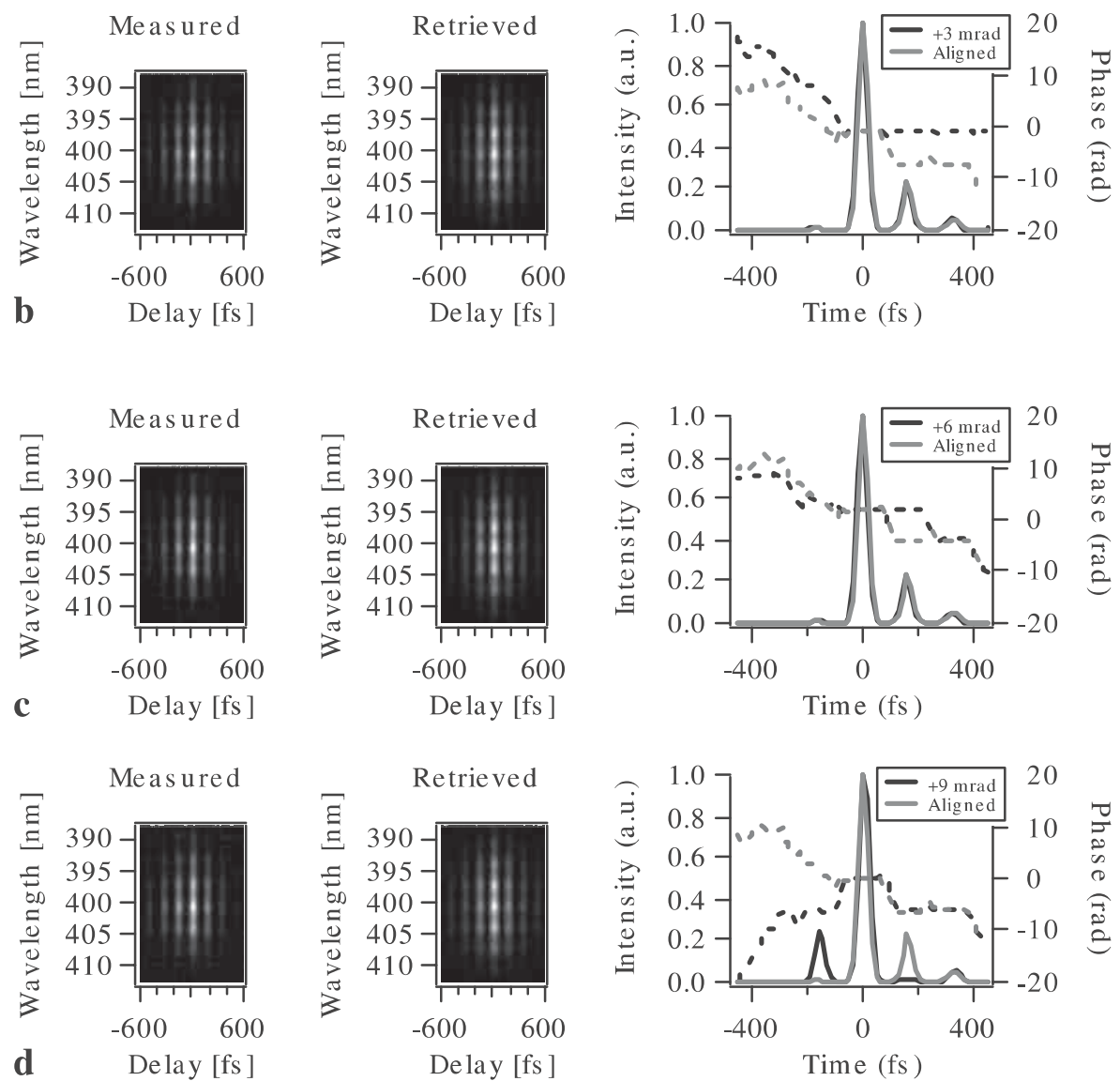